Discussion Paper No. 16-048

\title{
Measuring Patent Quality and National Technological Capacity in Cross-country Comparison
}

Philipp Boeing and Elisabeth Mueller

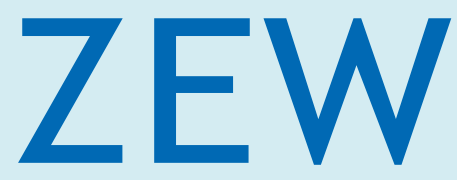

Zentrum für Europäische Wirtschaftsforschung $\mathrm{GmbH}$

Centre for European

Economic Research 
Discussion Paper No. 16-048

\title{
Measuring Patent Quality and National Technological Capacity in Cross-country Comparison
}

\author{
Philipp Boeing and Elisabeth Mueller
}

Download this ZEW Discussion Paper from our ftp server:

http://ftp.zew.de/pub/zew-docs/dp/dp16048.pdf

Die Discussion Papers dienen einer möglichst schnellen Verbreitung von neueren Forschungsarbeiten des ZEW. Die Beiträge liegen in alleiniger Verantwortung der Autoren und stellen nicht notwendigerweise die Meinung des ZEW dar.

Discussion Papers are intended to make results of ZEW research promptly available to other economists in order to encourage discussion and suggestions for revisions. The authors are solely responsible for the contents which do not necessarily represent the opinion of the ZEW. 


\title{
Measuring patent quality and national technological capacity in cross-country comparison
}

\author{
Philipp Boeing* and Elisabeth Mueller**
}

June 2016

\begin{abstract}
China recently surpassed the USA as the greatest global source of patent applications. However, without internationally comparable measures of patent quality it remains questionable whether China's patent expansion constitutes the rise of a new technological superpower. Our novel quality index is based on citations from international search reports and provides internationally comparable, quality-adjusted figures for applications made under the Patent Cooperation Treaty (PCT). We show that China's patent expansion has taken place to the detriment of patent quality. Weighting national PCT counts with our index reveals a widening gap between the technological capacities of China and the leading USA.
\end{abstract}

\section{JEL classification: $\mathrm{O} 32, \mathrm{O} 34$}

Keywords: patent quality, national technological capacity, cross-country comparison

\footnotetext{
* Centre of European Economic Research (ZEW), L7, 1, 68161 Mannheim, Germany; Research Center for Technological Innovation, Tsinghua University, Beijing, P. R. China. e-mail: boeing@zew.de ** German Graduate School of Management and Law, Bildungscampus 2, 74076 Heilbronn, Germany; Centre for Transformational Innovation, Swinburne University of Technology, Hawthorn, Australia; ZEW, Mannheim, Germany. e-mail: elisabeth.mueller@ggs.de
}

Acknowledgements: An earlier version of this paper was circulated under the title "Measuring patent quality in international comparison - Index development and application to China", ZEW DP 15-051. We acknowledge valuable feedback from Can Huang, Xibao Li, Georg Licht, Russell Thomson, Beth Webster, and Xiaobo Zhang. We thank conference and seminar participants at the ZEW Conference on Economics of Innovation and Patenting 2015, ZEW SEEK Conference 2015, OECD IP Statistics for Decision Makers 2015, Sino-German Workshop in Hangzhou 2015, APIC 2015, Peking University, Tsinghua University, Swinburne University of Technology, Chinese Academy of Social Science, Chinese State Information Center, Zhejiang University, and University Duisburg-Essen for helpful discussion. We thank patent examiners from the European Patent Office, IP Australia, and the German Patent and Trademark Office as well as Carlo Pandolfi, Director International Co-operation at European Patent Office, for sharing their insights with us. Marian Hafenstein, Evi Kröker, and Wu Taixing provided excellent research assistance. 


\section{Introduction}

Patent applications are a leading indicator of emerging technological prowess and indicate a global shift from the West to the East in recent years. Stimulated by national policy, e.g. patent subsidies, in 2011 China surpassed the USA as the greatest global source of patent applications (OECD 2014). Since 2013, China has ranked third in terms of applications made under the Patent Cooperation Treaty (PCT), typically preceding the international commercialization of valuable inventions (WIPO 2014a, Grupp and Schmoch 1999). However, without comparable information on patent quality it remains questionable whether China's rapid expansion in PCT applications constitutes the rise of a new technological superpower. Although there is a consensus in the literature that frequent citations by subsequent patents indicate higher quality (Jaffe and Rassenfosse 2016, Harhoff et al. 1999, Trajtenberg 1990) and provide the best approximation of patent quality (Gambardella et al. 2008, Reitzig 2004), currently available quality measures do not provide unbiased country comparisons.

In this paper we develop a quality measure based on citations from international search reports (ISRs), generated during the international phase of PCT applications. Under the PCT system, applicants can simultaneously seek protection in up to 148 countries (WIPO 2014a). Our main index, which only considers citations of foreign PCT applications, not only allows for cross-country comparisons of patent quality but is also unaffected by national policies. Covering the start of China's patent expansion, we apply our indices to the population of PCT applications filed between 2001 and 2009. For external validation of our measure, we calculate the indices for patent portfolios of all domestic firms listed in mainland China and regress those indices on relevant firm characteristics, such as R\&D.

We find that China's PCT expansion has taken place to the detriment of patent quality. According to our main index, China's average patent quality only reaches $32.1 \%$ of non- 
Chinese applicant countries and declines from $44.9 \%$ to $30.4 \%$ between 2001 and 2009 . In global comparison, the USA leads with an average value of $123.3 \%$, followed by Korea (93.5\%), Germany (71.9\%), and Japan (59.6\%). We measure national technological capacity by quality-adjusted patent counts, i.e. by multiplying PCT counts with our index, and confirm the leading position of the USA. Without quality adjustment, China's national technological capacity takes the third position, thereby overtaking Germany and Korea. If quality adjustment is applied, China remains in the fifth position and a widening gap between China and the leading USA is revealed. Regression results confirm that foreign PCT applications more often cite patents from Chinese firms with more extensive $R \& D$ but question the reliability of citations from Chinese PCT applications as quality measure.

The contributions of this paper are twofold. First, we develop a measure of patent quality that allows for cross-country comparisons. Our indices have a wide applicability. Beyond the application in this study, they may be used to measure the quality of national patents for any country included in the minimum documentation required for prior art search during the international phase. Second, we provide novel evidence on the quality of China's patents and technological capacity. While the policy-driven expansion of Chinese patent applications has occurred at the cost of quality, its technological capacity has increased less than would be expected if one considers only the number of patents applied for. Our results reveal that the number of Chinese patent applications and citations thereof are questionable measures of innovation levels and quality, respectively, and emphasize that measures stop serving as reliable measures if they become the target of policy (Goodhart 1975, Lucas 1976).

Prior literature has investigated the quality of Chinese patents on the basis of citationbased measures. Kwon et al. (2014) analyze patents granted at the US Patent and Trademark Office (USPTO) and find that patents with Chinese inventors closed the citation gap to patents with US-American inventors between 2000 and 2009. However, the comparability of 
patents from China and the US is limited because firms tend to select only their more valuable inventions for protection abroad. Therefore Chinese patents are a positively selected sample. Branstetter et al. (2015) take a different angle by investigating the role of inventors and patent owners. Of patents granted at the USPTO with involvement from either Chinese inventors or firms, the ones with non-Chinese co-inventors or multinational firms as patent owners receive more citations compared to the fully Chinese patents.

The remainder of the paper is organized as follows. In section 2, we develop our measure of patent quality that allows for unbiased cross-country comparison. In section 3 we apply the indices to the data and show results for patent quality, national technological capacities, and the external validation of our indices. Finally, section 4 offers a brief discussion of policy implications.

\section{Measurement of patent quality}

A challenge in assessing patents or in measuring national technological capacity using patent applications is that patents vary in their commercial value and technological impact. Evidence suggests that most patents are almost worthless, whereas only a few represent technological breakthroughs of high value (Gambardella et al. 2008). If explicit value information is not available, measures based on citations provide the best approximation of patent quality (Gambardella et al. 2008, Reitzig 2004). Frequent citations by subsequent patents indicate higher quality, given that differences affecting citation propensity, e.g. technology, are controlled for (Jaffe and Rassenfosse 2016, Harhoff et al. 1999, Trajtenberg 1990). In cross-country studies, however, the comparability of citation counts has several limitations. First, as applicants only select more valuable patents for protection abroad (due to higher filing and translation costs), a direct comparison of domestic and foreign applications is hardly informative (Harhoff et al. 2003). Second, heterogeneous examination practices lead 
to significant variation in citation counts generated across national patent offices (Michel and Bettels 2001). Third, patent examiners are biased towards citing domestic patents from their home country (Michel and Bettels 2001, Bacchiocchi and Montobbio 2010).

We ensure comparability by exclusively relying on citations generated by ISRs during the international phase of PCT applications. Under the PCT system, applicants can simultaneously seek protection in up to 148 countries, typically preceding the international commercialization of valuable inventions (Grupp and Schmoch 1999, WIPO 2014a). A search for prior art occurs in the international phase within 30 months after filing the application. National patent offices act as international search authorities (ISAs) where all examiners follow the same strict examination rules from the World Intellectual Property Organization (WIPO) when drafting an ISR (WIPO 2014b). More details on the PCT process can be found in the appendix.

Our quality measure allows for technology-specific cross-country comparisons. The ISR index $x_{\gamma \kappa}$ defines the quality level of PCT applications, where the home country of the first applicant $\mathrm{c}=\gamma$ and technology class $\mathrm{k}=\kappa$. The index is calculated at the annual level but we omit time indices to simplify notation.

$$
\text { ISR index } \gamma_{\gamma \kappa}=\frac{\frac{1}{N_{\gamma \kappa}} \sum_{i=1 \mid i \in c=\gamma}^{I}\left(\sum_{j=1}^{I} \text { ISRcites }_{i j}\right) * \omega_{i \kappa}}{\frac{1}{N_{\bar{\gamma} \kappa}} \sum_{l=1 \mid l \in c=\bar{\gamma}}^{I}\left(\sum_{j=1}^{I} \text { ISRcites }_{l j}\right) * \omega_{l \kappa}}
$$

$\omega_{i \kappa}$ is the proportion of patent $i$ within technology class $\kappa . N_{\gamma \kappa}$ is the sum of $\omega_{i \kappa}$ over all patents of country $\gamma$, i.e. $N_{\gamma \kappa}=\sum_{i=1 \mid i \in c=\gamma}^{I} \omega_{i \kappa}$. The comparison group is denoted by $\bar{\gamma}$ and contains all patents that do not belong to country $\gamma$. The indicator function ISRcites $_{i j}$ equals one if application $i$ is cited by application $j$ within the defined time window and zero otherwise. $j$ ranges from 1 to $I$, i.e. it covers the full population of PCT applications.

The country-level index is obtained by averaging ISR indices across technology classes: 


$$
\operatorname{ISR} \operatorname{index}_{\gamma}=\frac{1}{N_{\gamma}} \sum_{k=1}^{K} N_{\gamma k} * \text { ISR index } \text { in }
$$

$N_{\gamma}$ is the total number of patents of country $\gamma$. A value of the ISR index of larger (smaller) than $100 \%$ signifies quality above (below) the comparison group.

From now on we drop the country subscript $\gamma$ and instead use the subscript to indicate the following citation types: foreign citations $\mathrm{F}$, domestic citations $\mathrm{D}$, and self citations $\mathrm{S}$. The indicator function ISRcites $i j$ of our main index F $_{\mathrm{F}}$ only considers non-self-citations received by foreign countries, i.e. from countries other than the applicant country. In addition to non-selfcitations from foreign countries considered in index $_{\mathrm{F}}$, the alternative index $\mathrm{FD}_{\mathrm{FD}}$ also accounts for non-self-citations of domestic origin, which measure the technological self-reliance of an economy. By also considering self-citations, index $\mathrm{FDS}_{\mathrm{F}}$ acknowledges the extent to which an applicant builds on own prior art (Hall et al. 2005). Note that only our main index $\mathrm{F}_{\mathrm{F}}$ is invariant with respect to national policy as it relies only on citations generated outside of national boundaries

\section{Empirical analysis}

\subsection{Data}

Covering the start of China's patent expansion in 2001, we consider the population of PCT applications with priority years between 2001 and 2009. The priority year indicates the year in which the first patent application for a specific invention was filed, irrespective of the chosen patent offices. Country allocations of applications are based on the address of the first applicant and only citations from distinct pairs of citing and cited patent families are considered. Self-citations are identified on the basis of DOCDB standard names from PATSTAT and EEE-PPAT applicant name harmonization (Magerman et al. 2006). We use the 3-digit level of the IPC classification (technology class) to categorize patents, and apply 
fractional counting to apportion patents that belong to more than one technology class. Given the trade-off between precision and timeliness, we limit the citation window to a still informative three years. For the validation of the quality indices we use panel data for all domestic firms listed on the stock markets of mainland China covering the years 2001-2009. For details on the firm data see Boeing et al. (2016).

\subsection{Main quality index}

Index $_{\mathrm{F}}$, with a mean value of $32.1 \%$, shows that China's patent quality is significantly below that of the comparison group, which consists mainly of high-income countries (Table 1). Between 2001 and 2009, the decline of index , from $44.9 \%$ to $30.4 \%$, is a result of the decrease in the average number of citations obtained by Chinese PCT applications; whereas the citations received by the comparison group remain relatively stable. In global perspective, the USA leads with an average value of $123.3 \%$, followed by Korea $(93.5 \%)$, Germany (71.9\%), Japan (59.6\%), and China (32.1\%). The respective comparison groups include all countries except the country of interest. Given that the probability of obtaining a foreign ISR citation is lower if a country has a larger share in worldwide PCT applications,

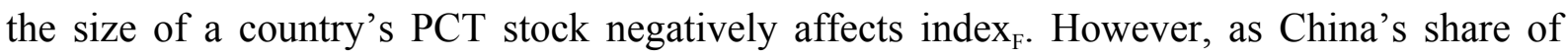
global PCT applications ( $2 \%$ in $2001,5 \%$ in 2009$)$ remained far below the US share $(40 \%$ in 2001, 29\% in 2009), the exclusion of domestic citations penalizes China less than the USA. Additional results concerning individual PCT applicant countries can be found in the appendix. 
Table 1. Index ${ }_{F}$ for major PCT applicant countries

\begin{tabular}{lccccc}
\hline \hline & China & $\begin{array}{l}\text { United } \\
\text { States }\end{array}$ & Korea & Germany & Japan \\
\hline \multicolumn{5}{c}{ Mean of index } \\
\hline 2001 & 44.9 & 115.9 & 74.4 & 67.1 & 73.1 \\
2002 & 34.2 & 122.7 & 87.0 & 72.0 & 70.1 \\
2003 & 38.8 & 113.5 & 73.9 & 75.6 & 66.9 \\
2004 & 34.4 & 105.4 & 89.3 & 75.9 & 65.1 \\
2005 & 41.0 & 114.4 & 104.8 & 72.2 & 61.1 \\
2006 & 30.7 & 116.1 & 108.5 & 68.5 & 57.7 \\
2007 & 29.0 & 127.0 & 105.4 & 66.5 & 57.0 \\
2008 & 29.8 & 134.9 & 95.7 & 73.3 & 53.4 \\
2009 & 30.4 & 158.8 & 80.4 & 76.1 & 49.1 \\
\hline Total & 32.1 & 123.3 & 93.5 & 71.9 & 59.6 \\
\hline \multicolumn{7}{c}{ Count of PCT applications 2001-2009 } \\
\hline Total & 34,738 & 360,653 & 44,314 & 138,212 & 201,633 \\
\hline
\end{tabular}

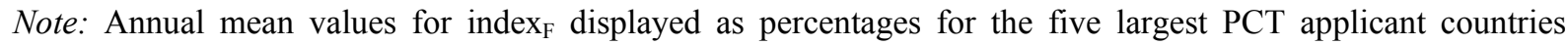
between 2001 and 2009. The respective comparison group includes the PCT population from all other countries.

Even though the core elements of PCT applications are published in English - i.e. abstract, title, search report, and text of drawings - other elements may only be available in the applicant's language. Potential language barriers deter patent examiners from identifying prior art from a specific country, and must therefore be accounted for. Comparing PCT applications of Chinese origin published in Chinese or English, we calculate a negative language bias for citation counts and obtain a correction factor of 1.11 for index $\mathrm{F}_{\mathrm{F}}$. After

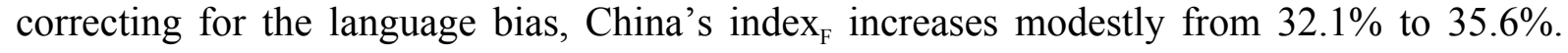
The appendix provides details about the role of language in the search for prior art and in the calculation of the correction factor. ${ }^{1}$

\footnotetext{
${ }^{1}$ The intuition behind the correction factor is as follows. From 2001 to 2009, there is no English publication or equivalent document in English available for $56 \%$ of PCT applications of Chinese origin. Only these applications require an adjustment. We quantify the language bias by calculating the share of non-self-citations from outside of China in all non-self-citations made before and after a document in English is available. As this share increases by 38 percentage points, from $31 \%$ to $69 \%$, we arrive at an adjustment factor of 1.38 . We apply this factor in full for PCTs that do not obtain an English equivalent during the full 3-year citation window and weigh the factor for PCTs that obtain an English equivalent within three years. Taking the relative importance of the different cases into account, we arrive at a final correction factor of 1.11 .
} 


\subsection{National technological capacity}

We measure national technological capacity by quality-adjusted patent counts, i.e. by multiplying PCT counts with the year- and country-specific mean value of index F $^{\text {. Figure } 1}$ shows the development of PCT applications with and without quality adjustment for the five largest applicant countries. Where exclusively patent counts are considered, the USA takes the leading position. This lead is increased when moving to the quality-adjusted PCT applications - highlighting the technological influence of the USA. Due to the 3-year citation window, we can only calculate the index up to 2009. However, extrapolating the qualityadjusted count by multiplying the patent counts with the average value of the index for the time period 2001-2009, enables us to obtain the quality-adjusted count up to 2013. Without quality adjustment, China takes the third position, thereby overtaking Germany and Korea. If quality adjustment is applied, China remains in the fifth position.

Figure 1. Annual PCT applications and national technological capacities

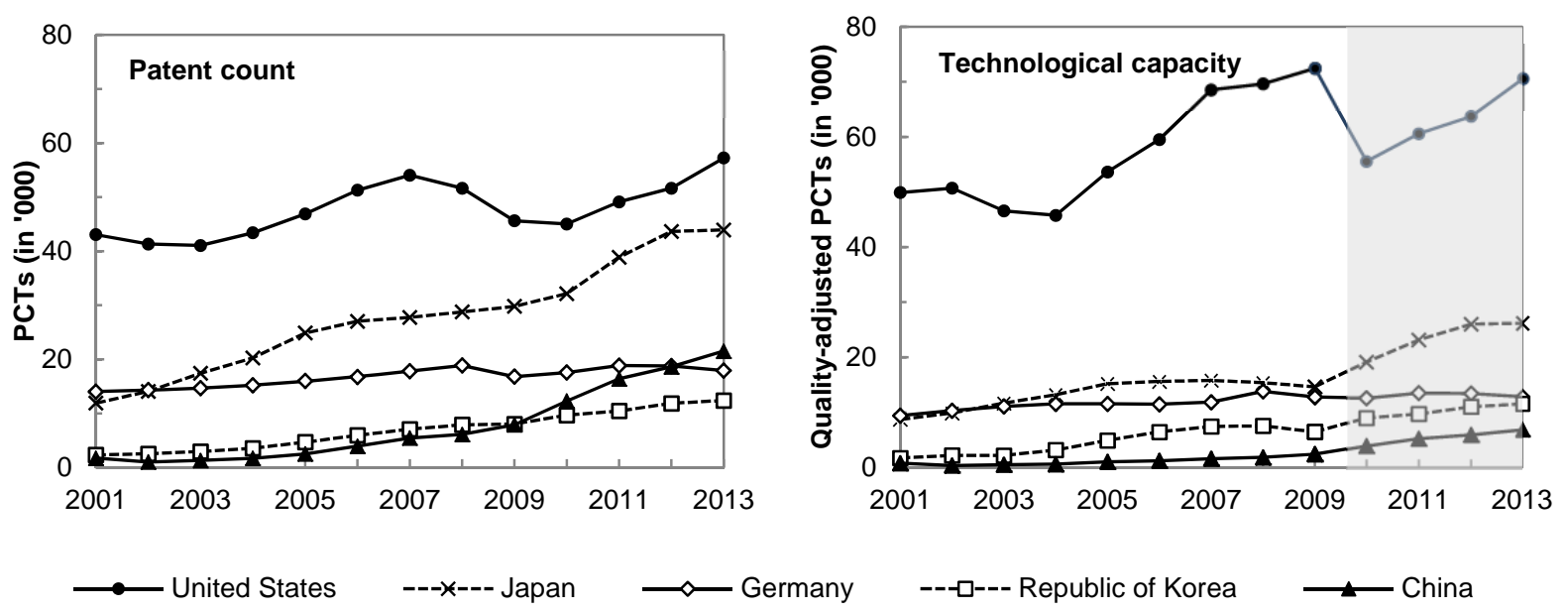

Note: The left figure shows the number of annual PCT applications for the five largest applicant countries between 2001 and 2013, as reported in WIPO (2014a). In the right figure quality adjusted PCT applications are shown. Numbers for 2010 onwards rely on an extrapolation. 


\subsection{Alternative quality indices}

Having reported our main results, we now expand the discussion to the two variations of the ISR index. In contrast to index $(32.1 \%)$, index ${ }_{\mathrm{FD}}(61.6 \%)$ and index $_{\mathrm{FDS}}(90.0 \%)$ indicate a Chinese quality level closer to that of the comparison group. In recent years, index $\mathrm{FD}_{\mathrm{F}}$ converges towards the comparison group while index $\mathrm{FDS}_{\text {surpasses }}$ it. The increasing discrepancy among indices reveals that in global comparison China relies disproportionally on domestically-developed technologies.

Table 2. Quality of Chinese PCT applications

\begin{tabular}{lcccc}
\hline \hline & Index $_{\mathrm{F}}$ & Index $_{\mathrm{FD}}$ & Index $_{\mathrm{FDS}}$ & PCT applications \\
\hline 2001 & 44.9 & 37.3 & 36.3 & 793 \\
2002 & 34.2 & 32.0 & 30.1 & 1,060 \\
2003 & 38.8 & 35.3 & 31.8 & 1,368 \\
2004 & 34.4 & 27.7 & 32.0 & 1,948 \\
2005 & 41.0 & 38.8 & 44.5 & 3,321 \\
2006 & 30.7 & 42.4 & 51.5 & 4,649 \\
2007 & 29.0 & 55.3 & 72.6 & 5,799 \\
2008 & 29.8 & 76.3 & 112.0 & 6,159 \\
2009 & 30.4 & 89.1 & 151.8 & 9,641 \\
\hline Total & 32.1 & 61.6 & 90.0 & 34,738 \\
\hline
\end{tabular}

Note: Annual mean values for index ${ }_{\mathrm{F}}$, index $\mathrm{x}_{\mathrm{FD}}$, and index $\mathrm{FDS}_{\mathrm{FD}}$ displayed as percentages for the years between 2001 and 2009. Index values are calculated for all Chinese PCT applications in comparison to all non-Chinese PCT applications.

We briefly summarize results for patent quality according to the six technology areas electrical engineering, chemistry, mechanical engineering, consumer goods and construction, instruments, and process engineering. Patents in the field of electrical engineering, which constitute with 57\% the majority of China's PCT applications, exhibit the largest difference between index $_{\mathrm{F}}(27.5 \%)$ and index $\mathrm{FDS}(97.6 \%)$. The dominance of electrical engineering is related to the activities of ZTE and Huawei, two globally operating ICT firms that together file one third of Chinese PCT applications. Both firms receive fewer foreign citations than the average Chinese application but, as is consistent with their large size, exhibit considerably more self-citations. Applications in chemistry, the second largest category with $13 \%$, display 
the smallest difference between index $_{\mathrm{F}}(38.4 \%)$ and index $\mathrm{FDS}(49.3 \%)$. In contrast to the complex technology electrical engineering, chemistry is a discrete technology and is not dominated by a few firms. The differences in the remaining technology areas are in between those reported for electrical engineering and chemistry.

\subsection{Validation of indices}

The expansion of Chinese PCT applications may contribute to higher levels and

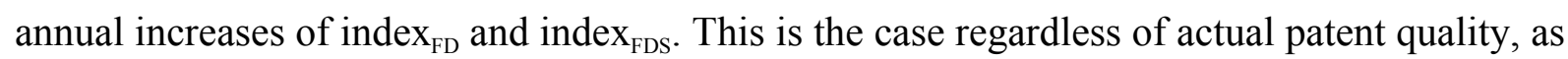
it simply means that there are more citing applications. With China as the focal country, the effect on domestic citations requires further investigation, whereas the effect on citations received by the international comparison group is negligible - only $3.8 \%$ of foreign non-selfcitations originate from China. As China's patent expansion has been driven by economic policy, in particular by patent subsidies (Lei et al. n.d., Li 2012, Dang and Motohashi 2015), we test whether citations resulting from Chinese applications are a reliable indicator of patent quality.

We calculate the ISR indices for patent portfolios of all domestic firms listed in mainland China and regress the indices on relevant firm characteristics. Table 3 provides descriptive statistics for firms with at least one PCT application and Table 4 shows the regression results. For the analysis we use a Tobit model because the dependent variable is truncated at zero. Given that R\&D is a leading input factor for patent quality, we expect that citations increase in the $R \& D$ stock of firms. While the significant relationship of index $x_{F}$ with R\&D confirms that foreign PCT applications more often cite patents from Chinese firms with more extensive $\mathrm{R} \& \mathrm{D}$, this relationship cannot be confirmed for index $\mathrm{FD}_{\mathrm{F}}$ and index $\mathrm{FDS}_{\text {. The }}$ reliability of Chinese citations as a measure of quality must therefore be questioned. 
Table 3: Descriptive statistics

\begin{tabular}{lcccccc}
\hline \hline Variable & Mean & Median & Std. dev. & Min & Max & Obs. \\
\hline Index $_{\mathrm{F}}$ & 43.3 & 0 & 135.2 & 0 & $1,350.4$ & 451 \\
Index $_{\mathrm{FD}}$ & 76.4 & 0 & 154.2 & 0 & 923.7 & 451 \\
Index $_{\mathrm{FDS}}$ & 87.5 & 0 & 139.4 & 0 & 890.4 & 451 \\
R\&D stock (million RMB) & 487.89 & 30.45 & 2,184 & 0 & 25,001 & 451 \\
PCT intensity & 3.505 & 0.825 & 8.673 & 0.005 & 100 & 451 \\
Domestic patent intensity & 55.179 & 8.589 & 216.640 & 0 & 2,920 & 451 \\
Employees & 20,237 & 3,126 & 68,680 & 10 & 539,168 & 451 \\
Firm age & 11.49 & 11 & 5.057 & 1 & 29 & 451 \\
Private ownership & 0.417 & 0 & & 0 & 1 & 451 \\
Provincial GDP/capita (RMB) & 30.996 & 29,447 & 15,786 & 5,905 & 66,006 & 451 \\
\hline
\end{tabular}

Note: Statistics based on firms with at least one PCT application. ISR indices are calculated as averages of annual patent applications.

Table 4: Results of Tobit estimations

\begin{tabular}{lccc}
\hline \hline & $(1)$ & $(2)$ & $(3)$ \\
\hline $\ln (\mathrm{R} \& D$ stock) & Index $_{\mathrm{F}}$ & Index $_{\mathrm{FD}}$ & Index $_{\mathrm{FDS}}$ \\
& $0.175^{* * *}$ & 0.038 & -0.004 \\
PCT intensity & $(0.063)$ & $(0.034)$ & $(0.026)$ \\
& $0.232^{* * *}$ & $0.082^{* *}$ & $0.051^{*}$ \\
Domestic patent intensity & $(0.049)$ & $(0.042)$ & $(0.028)$ \\
& $-0.006^{* *}$ & -0.001 & -0.001 \\
$\ln ($ employees) & $(0.003)$ & $(0.002)$ & $(0.001)$ \\
& 0.249 & 0.199 & $0.209 * *$ \\
$\ln ($ age) & $(0.230)$ & $(0.145)$ & $(0.094)$ \\
& -0.821 & -0.139 & -0.025 \\
Private ownership & $(0.672)$ & $(0.433)$ & $(0.287)$ \\
& 0.803 & -0.111 & -0.052 \\
$\ln$ (provincial GDP/capita) & $(0.670)$ & $(0.441)$ & $(0.291)$ \\
& -0.722 & -0.253 & -0.424 \\
Industry controls & $(0.640)$ & $(0.444)$ & $(0.338)$ \\
Year controls & Yes & Yes & Yes \\
\hline Observations (firms) & Yes & Yes & Yes \\
Log pseudo likelihood & $451(228)$ & $451(228)$ & $451(228)$ \\
\hline
\end{tabular}

Note: Analysis at firm-year level. The dependent variable is the average quality index of a firm's annual patent applications. Tobit estimation with standard errors clustered at the firm-level. Average marginal effects are reported in square brackets. Reference category for year is $2001 . * * *, * *, *$ indicate statistical significance at the $1 \%, 5 \%$, and $10 \%$ levels. 


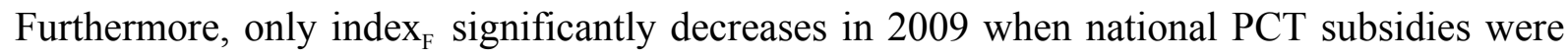
introduced (Chinese Ministry of Finance 2009). This decrease suggests that subsidies have a negative effect on patent quality. In a robustness check based on the Heckman two-step approach, which takes the selection into having at least one PCT application into account, we confirm the results of the Tobit models based on 12,575 observations for 1,743 listed firms. We conclude that index ${ }_{\mathrm{F}}$ is the most appropriate ISR index for measuring patent quality in the Chinese context. As economic policy has no direct influence on the index, changes in index reflect true variation in patent quality. Additional robustness exercises can be found in the appendix.

\section{Discussion}

We derive two implications from our analysis. First, the expansion of Chinese PCT applications has occurred at the cost of patent quality. Although China has undergone an unforeseen increase in patent applications (Porter and Stern 1999), its technological capacity has increased less than would be expected if one considers only the number of patents applied for. Quality-adjusted patent counts should therefore be used by policymakers and R\&D managers when comparing national technological capacities. Second, we empirically confirm that measures stop serving as reliable measures if they become the target of economic policy (Goodhart 1975, Lucas 1976). In response to subsidies, for example, Chinese applicants divide inventions into several applications in order to increase subsidy income (Lei et al. n.d.). Accordingly, Chinese patent applications and citations thereof are questionable measures of innovation levels and quality.

Having achieved a vast expansion in the number of applications made both domestically and abroad, the Chinese government must now ensure that China's rising R\&D investments, which are forecasted to overtake those of the USA in 2019 (OECD 2014), yield 
higher patent quality and thereby contribute to technological capacity and economic growth. From a global perspective, our analysis shows that Eastern technological capacity is not yet dominating, but the West's leading position largely depends on the performance of the USA. 


\section{References}

Bacchiocchi, E. and Montobbio, F., International knowledge diffusion and home-bias effect: do USPTO and EPO patent citations tell the same story. Scandinavian Journal of Economics 112, 441-470 (2010).

Boeing, P., Mueller, E. and Sandner, P., China's R\&D explosion - analyzing productivity effects across ownership types and over time. Research Policy 45, 159-176 (2016).

Branstetter, L., Li, G., and Veloso, F., "The Rise of International Coinvention" in The Changing Frontier: Rethinking Science and Innovation Policy, A. Jaffe and B. Jones, Eds. (University of Chicago Press, 2015), p. 135-168.

Chinese Ministry of Finance, "Interim measures for the administration of special funds for subsidizing a foreign patent application" (Publication No. 567, 2009).

Dang, J. and Motohashi, K., Patent statistics: a good indicator for innovation in China? Patent subsidy program impacts on patent quality. China Economic Review 35, 137-155 (2015).

Gambardella, A., Harhoff, D., and Verspagen, B., The value of European patents. European Management Review 5, 69-84 (2008).

Goodhart, C. A. E., Problems of monetary management: the U.K. experience. Papers in Monetary Economics (Reserve Bank of Australia, 1975).

Grupp, H. and Schmoch, U., Patent statistics in the age of globalization: new legal procedures, new analytical methods, new economic interpretation. Research Policy 28, 377-396 (1999).

Hall, H., Jaffe, A., and Trajtenberg, M., Market value and patent citations. RAND Journal of Economics 36, 16-38 (2005).

Harhoff, D., Narin, F., Scherer, F. M., and Vopel, K., Citation frequency and the value of patented inventions. Review of Economics and Statistics 81(3), 511-515 (1999).

Harhoff, D., Scherer, F. M., and Vopel, K., Citations, family size, opposition and the value of patent rights. Research Policy 32, 1343-1363 (2003).

Jaffe, A. B. and Rassenfosse, G. de, Patent citation data in social science research: overview and best practices, NBER Working Paper 21868 (2016).

Kwon, S., Lee, J., and Lee, S., International trends in technological progress: stylized facts from patent citations. CEM Working Paper, CWP 16/14. (2014).

Lei, Z., Sun, Z., and Wright. B., Patent subsidies and patent filing in China. University of California, Berkeley, mimeo (n.d.).

$\mathrm{Li}, \mathrm{X}$., Behind the recent surge of Chinese patenting: an institutional view. Research Policy 41, 236-249 (2012).

Lucas, R. E., Econometric policy evaluation: a critique, Carnegie-Rochester Conference Series on Public Policy. 1, 19-46 (1976). 
Magerman, T., Looy, B.V. and Song, X., Data production methods for harmonized patent statistics: patentee name harmonization. Eurostat Working Paper and Studies, Luxembourg (2006).

Michel, J. and Bettels, B., Patent citation analysis: a closer look at the basic input data from patent search reports. Scientometrics 51, 185-201 (2001).

OECD, “OECD Science, Technology and Industry Outlook 2014” (OECD Publishing 2014).

Porter, M. and Stern, S., "The new challenge to America's prosperity: findings from the innovation index" (Council on Competitiveness, 1999).

Reitzig, M., Improving patent valuations for management purposes: validating new indicators by analyzing application rationales. Research Policy 33, 939-957 (2004).

Trajtenberg, M., A penny for your quotes: patent citations and the value of innovations. RAND Journal of Economics 21, 172-187 (1990).

WIPO, "Patent cooperation treaty yearly review - the international patent system" (WIPO, 2014a).

WIPO, "Patent cooperation treaty - international search and preliminary examination guidelines" (WIPO, 2014b). 


\title{
Appendix \\ Measuring patent quality and national technological capacity in cross-country comparison
}

\author{
Philipp Boeing and Elisabeth Mueller
}

\section{A. Supplementary Background Information}

\section{A. 1. The PCT application process}

Under the PCT system, applications are filed with a competent Receiving Office (RO). During the 30 months following the priority date, PCT applications remain in the international phase. The designated International Search Authority (ISA) publishes the International Search Report (ISR) 18 months after the priority date. References to prior art are contained in the ISR, and the strict PCT guidelines for these references are identical for all ISAs. After 30 months have elapsed, the application enters the national phase in which national patent offices perform additional search and examination before making the grant decision. Citations in the national phase may differ from ISR citations as the former follow national guidelines. In order to restrict the citations to one institutional setting, we do not consider citations generated during the national phase for our quality index.

The home country of the applicant determines which ROs and ISAs may be approached for the processing of the application. The PCT procedure stipulates that Chinese applicants must file PCT applications with the Chinese Patent Office (SIPO) as the Receiving Office (RO). SIPO is also the only competent office to act as ISA and write an International Preliminary Examination Report (IPER). 


\section{A. 2. Determination of prior art for PCT applications}

In the PCT system, applicants are encouraged to provide references to prior art. The description of the application should "indicate the background art which, as far as known to the applicant, can be regarded as useful for the understanding, searching and examination of the invention, and, preferably, cite the documents reflecting such art" (Rule 5 of WIPO 2014c). This PCT rule strikes a balance between the regulations of the US Patent and Trademark Office (USPTO) and the European Patent Office (EPO). Whereas the USPTO requires applicants to provide references to all relevant prior art that they are aware of, the EPO requires only that examiners, and not applicants, carry out this task (Michel and Bettels 2001). In the PCT system it is ultimately the examiner who, according to strict guidelines, determines which references are included in the ISR. Such selected references are an appropriate measure of patent quality as they constitute an evaluation by a third party, namely by the examiner, of the technical and legal relationships between patents. Prior work has indicated that examiner citations show a much stronger correlation with patent value than applicant citations (Hegde and Sampat 2009).

The search for prior art for PCT applications follows internationally identical guidelines. Citations are therefore internationally comparable and are not influenced by the nationality of the ISA conducting the search. The search guidelines explain in detail how citations are to be selected by the examiners (WIPO 2014b, §15.63-15.67). Examiners are encouraged, for example, to cite only the most relevant documents and, in the case that several members of one patent family are available, to cite documents in the language of the application (WIPO 2014b, §15.64). As we aggregate citations at the family level, our quality index is not influenced by which family member is ultimately cited. The international comparability of the index is further upheld by the fact that the search for prior art is highly concentrated among a few ISAs. According to WIPO (WIPO 2014a, p. 69), the top five ISAs 
were responsible for more than 90\% of ISRs in 2013 (EPO 37.7\%, Japanese Patent Office (JPO) 20.7\%, Korean Patent Office (KPO) 14.8\%, SIPO 11.6\%, USPTO 8.1\%).

\section{A. 3. Potential language barriers in the selection of prior art}

Potential language barriers deter patent examiners from identifying prior art from a specific country and must therefore be accounted for in international comparisons of patent quality. Patent examiners typically begin their search for prior art with a keyword search in English, regardless of which searches, i.e. searches for the ISR or searches within national procedures, are conducted. Thorough prior art searches are, however, only possible if documents published in other languages can be found. The PCT system provides an English translation of the main parts of PCT applications; namely title, abstract, international search report, and any text relating to figures for all PCT applications not published in English (WIPO 2014c, Rule 48.3 (c)). The abstract plays a key role in the search. According to Rule 8.3 (WIPO 2014c) "The abstract shall be so drafted that it can efficiently serve as a scanning tool for purposes of searching in the particular art, especially by assisting the scientist, engineer or researcher in formulating an opinion on whether there is a need for consulting the international application itself'. PCT applications, even if not originally published in English, are therefore easily identifiable as potentially relevant prior art.

According to further guidelines of the PCT system, patent examiners conducting the international search must have access to the minimum documentation, which specifies the set of prior art that examiners must be able to search. PCT applications, irrespective of the publication language, belong to the minimum documentation and are therefore fully accessible during the search process. Patent applications belonging to the minimum documentation are typically included in the databases most commonly used for search by 
examiners (e.g. Derwent World Patents Index (DWPI), Chemical Abstracts Service (CAS), and EPOQUE at the EPO).

When it comes to deciding whether a document is ultimately to be included as prior art, patent examiners aim to consult the full application text. Examiners working at ISAs have access to a number of tools when dealing with prior art published in Chinese that has no English equivalent, i.e. if the patent family does not contain an application filed in another country in English. At the EPO, for example, as a first line of support, examiners are able to call on colleagues who are native Chinese speakers to help them determine the relevance of a document. If the document is deemed relevant, examiners may then request a human translation of the full text. Since 2008, machine translations of Chinese documents have served as an intermediate step prior to requesting a human translation. Indeed, since April 2008, SIPO has provided the public with free machine translations of the full texts of its patents through its website (Kaemmer 2010). Since 2012, examiners at the EPO have been able to submit documents for machine translation from Chinese into English through their search system EPOQUE. This improvement has taken place after the end of our observation period.

By conducting interviews with patent examiners of several patent offices, we have tried to identify possible biases against citing prior art originally published in Chinese. In making their decision as to whether prior art written in Chinese is relevant, examiners claim that they are not influenced by their familiarity with the country or applicant. Overall, examiners are eager to find the most appropriate prior art. It has been acknowledged by a subgroup of examiners, however, that under time pressure, prior art in Chinese may be less likely to be included in the search report. This is particularly the case if alternative documents in English are readily available, and if these provide sufficient ground to negate a claim or to reject an application in its entirety. 
As the majority of patent examiners working at non-Chinese ISAs have no command of Chinese, we address the insights from our interviews by quantifying the related language bias. From 2001 to 2009, the majority (91\%) of PCT applications made by Chinese applicants were published in Chinese with the remainder (9\%) published in English. However, at the time of publication, there is no equivalent document in English for only $56 \%$ of PCT applications of Chinese origin.

We quantify the language bias by calculating the share of non-self-citations from outside of China in all non-self-citations made before and after an English equivalent is available. ${ }^{2}$ As this share increases by 38 percentage points, from $31 \%$ to $69 \%$, we arrive at an adjustment factor of 1.38 for the set of PCTs that do not obtain an English equivalent during the full 3-year citation window (1,095 days). For PCTs that obtain an English equivalent within three years, we weight the adjustment factor by $664 / 1,095$ to account for the average time period after which an English equivalent is obtained, namely 664 days after publication. PCTs with English equivalents at publication are not subject to bias and require no correction. Taking the relative importance of the three groups into account, our weighted correction factor for ISR index $\mathrm{F}$ is $1.11 .^{3}$ As the increase of foreign citations is partially a result of the time required for the geographic diffusion of knowledge (Jaffe et al. 1993, Peri 2005), the calculated correction factor represents an upper limit for the pure language bias.

\footnotetext{
${ }^{2}$ Self-citations from outside China may occur if an international subsidiary of a Chinese firm cites inventions of its mother company.

${ }^{3}$ The size of the language barrier is substantial for affected applications but the overall effect is smaller as not all applications are affected to the full extend. A more detailed analysis of the role of language barriers for the content of search reports requires future research.
} 


\section{A. 4. Impact of China's patent policies}

China's patent expansion follows quantitative targets set by governmental economic policies. ${ }^{4}$ In support of these targets, numerous provincial and sub-provincial subsidy programs incentivize patenting, often by supporting domestic as well as international applications. In 2009, the central government also introduced subsidies for PCT patents (Chinese Ministry of Finance 2009). ${ }^{5}$ Research not only indicates a positive influence of patent subsidies on patent expansion (Li 2012), but also shows that in response to subsidies, applicants divide inventions into several applications in order to increase subsidy income (Lei et al. n.d.). Interestingly, these studies do not find a decrease in the grant rate. Consequently, it seems that China's economic policy not only increases the number of patent applications made, but also lowers examination standards, therefore making grant rates an unreliable measure of patent quality. ${ }^{6}$

SIPO itself voiced its dissatisfaction in regard to this development. It has recently published two documents that criticize the abundance of provincial and city-level subsidies for patent applications and the low examination standards at provincial and city-level patent offices (State Intellectual Property Office 2013, 2014). SIPO suggests that increases in the number of applications are detrimental to average patent quality and demands stricter monitoring of examination standards. Furthermore, SIPO proposes that application-based subsidy schemes are replaced by schemes based on actual grants, thereby reducing excessive applications and favoring patent quality over quantity.

\footnotetext{
${ }^{4}$ Recent cornerstones of China's innovation policy include the "Medium- to Long-term Plan for Science and Technology Development (2006-2020)," the "National Patent Development Strategy (2011-2020)," and the current "Five-Year Plan for Science and Technology Development."

${ }^{5}$ Applications in up to five countries (regions) are subsidized with up to 100,000 RMB each (ca. 14,600 USD, exchange rate of 31.12.2009). Exceptions are possible for projects involving significant innovation. Subsidies should mainly cover examination fees, patent agent service fees, and renewal fees. Applications are only subsidized once.

${ }^{6}$ The effect of China's economic policy on examination standards may be direct, if provincial policy makers encourage constant grant rates, or indirect, if examiners are confronted with an increasing number of applications - leading to considerably less time for examination, which negatively affects the probability of discovering prior art.
} 


\section{B. External validation of ISR indices - Additional analysis for listed firms}

\section{B. 1. Data}

In order to externally validate our ISR indices we calculate them for the applications of Chinese firms and relate them to firm characteristics. We observe the population of domestic Chinese firms listed at the two stock exchanges in Shanghai and Shenzhen between 2001 and 2009. Due to governmental stock issuance quotas, the listed firms are adequately representative of the Chinese economy's industrial composition, with large manufacturing firms strongly represented in more developed Coastal regions (Pistor and Xu 2005). It should be noted that the China Securities Regulatory Commission only allows listings of "domestic" Chinese firms, i.e. the percentage of total shares held by foreign parties can not exceed $20 \%$. This implies that foreign subsidiaries operating in China are excluded from firm-level analysis.

Our panel data of standard firm characteristics is drawn from the following sources. R\&D expenditures for the years from 2001 to 2005 are collected manually from annual reports (CNINFO). For the years from 2006 to 2009 they are obtained from the Chinese database WIND. Patent data is obtained from the April 2013 version of the EPO Worldwide Patent Statistical Database (PATSTAT) and matched to firm data (Boeing et al. 2016). The number of employees is obtained from Datastream and the date of firm establishment and industry affiliation from WIND. Information on state ownership is obtained from RESSET. Provincial GDP per capita is obtained from the Chinese National Bureau of Statistics.

\section{B. 2. Regression analysis}

\section{B. 2.1 Dependent variables}

We use regression analysis for the external validation of the ISR indices. The dependent variables include index ${ }_{\mathrm{F}}$, index $\mathrm{FD}_{\mathrm{FD}}$, index $\mathrm{FDS}_{\mathrm{FS}}$ and, in addition, two indices that exclusively 
consider domestic or self-citations. As a first step, we compare the patent quality in the sample of listed firms (Table B1) with the quality of all Chinese PCT applications (Table 1). Whilst the values for index $\mathrm{F}_{\mathrm{F}}$ and index $\mathrm{FD}_{\mathrm{FD}}$ are very similar, we see a larger value for index $\mathrm{FDS}_{\text {. }}$ This is to be expected as listed firms are larger than average firms. We then move from the patent level to the firm-year level and calculate the average index value over all PCT applications filed by a firm in a given year for each observation. The statistics for our main indices are provided in Table $\mathrm{B} 2$. Index $\mathrm{F}_{\mathrm{F}}$ has an average value of $43.3 \%$, index $\mathrm{FD}_{\mathrm{FD}}$ of $76.4 \%$, and index $\mathrm{FDS}_{\mathrm{FD}}$ of $87.5 \%$. The averages in Table $\mathrm{B} 2$ differ from those in Table $\mathrm{B} 1$ due to weighting. At the patent level, each patent has the same weighting, whereas at firm-year level each firm observation has the same weighting regardless of the size of the patent stock.

\section{B. 2.2 Firm characteristics and standard controls}

We briefly discuss the descriptive statistics of the firm characteristics for the 228 firms with PCT applications for which we have 451 observations (Table B2). Employing the perpetual investment method, we calculate deflated R\&D stocks based on an assumed annual growth rate of $R \& D$ of $20 \%$ and a standard annual depreciation rate of $15 \%$. The resulting median R\&D stock has a value of 30.45 million RMB. PCT and domestic patent intensity are calculated as the respective patent stocks of the firm depreciated by an annual rate of $15 \%$ and scaled by '000 employees. We find that intensity is much smaller for PCT than for domestic applications. Firms with PCT applications are relatively large; the median number of employees is 3,126 and the firms themselves tend to be relatively young, with a median age of 11 years. We broadly differentiate between firms with and without any government ownership and find, that according to this differentiation, $41.7 \%$ of observations are private firms. To allow for differences in China's economic development, we control for deflated GDP per 
capita at the provincial level. In addition, we account for macro-economic shocks and industry-specific effects by including year- and industry-dummies, respectively.

\section{B. 2.3 Results}

In Table B3 we estimate a Tobit model with standard errors clustered at the firm-level. For the analysis we use a Tobit model because the dependent variable is truncated at zero. Average marginal effects are listed to the right of coefficients. In Model (1) we regress index $\mathrm{F}_{\mathrm{F}}$ on our set of firm characteristics and standard controls. We find positive and highly significant effects $(\mathrm{p}<0.01)$ for the R\&D stock and PCT intensity, but a significantly negative effect $(\mathrm{p}<0.05)$ for domestic patent intensity. A $1 \%$ increase in the R\&D stock corresponds to an increase in the quality index by 3.6 percentage points. Adding one unit to the PCT intensity increases index $\mathrm{F}_{\mathrm{F}}$ by 4.7 percentage points, whereas adding one unit to the domestic patent intensity decreases index $\mathrm{F}_{\mathrm{F}}$ by 0.1 percentage points.

These results indicate a positive and economically important relationship between $\mathrm{R} \& \mathrm{D}$, which is the most important input factor for innovation, and patent quality. The opposite signs for PCT intensity and domestic patent intensity suggest that international and domestic patenting strategies are differently related to patent quality. Further, our year dummies show a negative time trend, which becomes more pronounced in recent years and turns weakly significant $(\mathrm{p}<0.1)$ with the introduction of national PCT subsidies in 2009. In line with the sizable expansion in PCT applications between 2001 and 2009, it seems plausible that the increase in quantity coincides with a decrease in quality.

In Model (2), we change the dependent variable to index $\mathrm{FD}_{\mathrm{FD}}$. With the exception of the PCT intensity, which remains positive and significant $(\mathrm{p}<0.05)$, all remaining regressors become insignificant. In Model (3) we change the dependent variable to index ${ }_{\mathrm{FDS}}$. The PCT 
intensity remains positive but is only weakly significant $(p<0.1)$. The expected positive correlation between firm size and self-citations is also confirmed $(\mathrm{p}<0.05)$.

Given that the expected correlation between $R \& D$ stock and patent quality is confirmed only for index $x_{F}$, we aim to estimate the effect of the R\&D stock on two indices that exclusively consider either domestic or self-citations in Model (4) and (5). These models fail to show a significant relation between $R \& D$ stock and patent quality. Whilst we fail to identify any significant effects in Model (4), Model (5) reveals a positive and highly significant $(\mathrm{p}<0.01)$ correlation of ISR self-citations with PCT intensity and firm size (measured by the number of employees). In addition, the domestic patent intensity has a negative and highly significant $(\mathrm{p}<0.01)$ effect. Model (5) resembles the findings of Model (3) with higher significance levels and larger marginal effects. In addition, Model (5) suggests that the inventive activity of firms generates significantly more self-citations in the years 2008 $(\mathrm{p}<0.05)$ and $2009(\mathrm{p}<0.01)$.

To summarize, these findings suggest that index $\mathrm{F}_{\mathrm{F}}$ is the preferable measure of patent quality in China because domestic citations and self-citations are not correlated with $\mathrm{R} \& \mathrm{D}$ stocks. We therefore perform additional robustness tests for index $x_{\mathrm{F}}$, which are reported in Table B4. For ease of reference we repeat the standard Tobit results as Model (1). In Model (2) we conduct a random effects Tobit estimation with the Chamberlain-Mundlak device and confirm a positive and highly significant correlation between index $\mathrm{F}_{\mathrm{F}}$ and the R\&D stock. This random-effects model achieves consistent results even if the time-invariant error term is not independent from our time-variant regressors. The model includes the average value of timevariant regressors as additional controls in the regression specification. The magnitude of the marginal effect is comparable to the magnitude estimated in our standard Model (1).

In Models (3a) and (3b) we not only consider firms with PCT applications but include all listed firms. We estimate the selection and outcome equation of a Heckman two-step 
selection model using the number of employees as an exclusion restriction. Our results show that large firms are more likely to file PCTs. Indeed, the number of employees has a nontrivial and positive effect at the $1 \%$ significance level on selection. As expected, $\rho$ confirms a positive correlation of residuals in the selection and outcome equation. Nonetheless, the coefficient of $\lambda$, which is the covariance of the error terms of both equations, is not significant. This finding shows that additional unobservables are unlikely to induce significant selection bias. We find that the R\&D stock has a positive and highly significant effect $(\mathrm{p}<0.01)$ on the probability of filing at least one PCT application (Model 3a) and a positive and highly significant effect $(\mathrm{p}<0.01)$ on receiving foreign ISR citations (Model $3 b)$. The marginal effect of the R\&D stock in Model (3b) is smaller than in Model (1), as the first stage in Model (3a) already partly captures its influence on PCT applications. 
Table B1: Quality of PCT applications of Chinese listed firms

\begin{tabular}{lcccc}
\hline \hline & Index $_{\mathrm{F}}$ & Index $_{\mathrm{FD}}$ & Index $_{\mathrm{FDS}}$ & Obs. \\
\hline 2001 & 60.3 & 85.3 & 94.2 & 53 \\
2002 & 56.6 & 56.5 & 68.3 & 102 \\
2003 & 42.3 & 52.7 & 48.2 & 159 \\
2004 & 81.7 & 78.1 & 68.0 & 195 \\
2005 & 56.0 & 69.9 & 56.0 & 347 \\
2006 & 55.7 & 61.0 & 65.2 & 429 \\
2007 & 46.7 & 74.1 & 102.4 & 710 \\
2008 & 23.1 & 62.4 & 144.7 & 871 \\
2009 & 18.7 & 61.2 & 152.4 & 2,318 \\
\hline Total & 33.1 & 64.3 & 121.9 & 5,184 \\
\hline
\end{tabular}

Note: Mean values of variables displayed as percentages.

Table B2: Descriptive statistics

\begin{tabular}{lcccccc}
\hline \hline Variable & Mean & Median & Std. dev. & Min & Max & Obs. \\
\hline Index $_{\mathrm{F}}$ & 43.3 & 0 & 135.2 & 0 & $1,350.4$ & 451 \\
Index $_{\mathrm{FD}}$ & 76.4 & 0 & 154.2 & 0 & 923.7 & 451 \\
Index $_{\mathrm{FDS}}$ & 87.5 & 0 & 139.4 & 0 & 890.4 & 451 \\
R\&D stock (million RMB) & 487.89 & 30.45 & 2,184 & 0 & 25,001 & 451 \\
PCT intensity & 3.505 & 0.825 & 8.673 & 0.005 & 100 & 451 \\
Domestic patent intensity & 55.179 & 8.589 & 216.640 & 0 & 2,920 & 451 \\
Employees & 20,237 & 3,126 & 68,680 & 10 & 539,168 & 451 \\
Firm age & 11.49 & 11 & 5.057 & 1 & 29 & 451 \\
Private ownership & 0.417 & 0 & & 0 & 1 & 451 \\
Provincial GDP/capita (RMB) & 30.996 & 29,447 & 15,786 & 5,905 & 66,006 & 451 \\
\hline
\end{tabular}

Note: Statistics based on firms with at least one PCT application. ISR indices are calculated as averages of annual patent applications. 
Table B3: Results of Tobit estimations

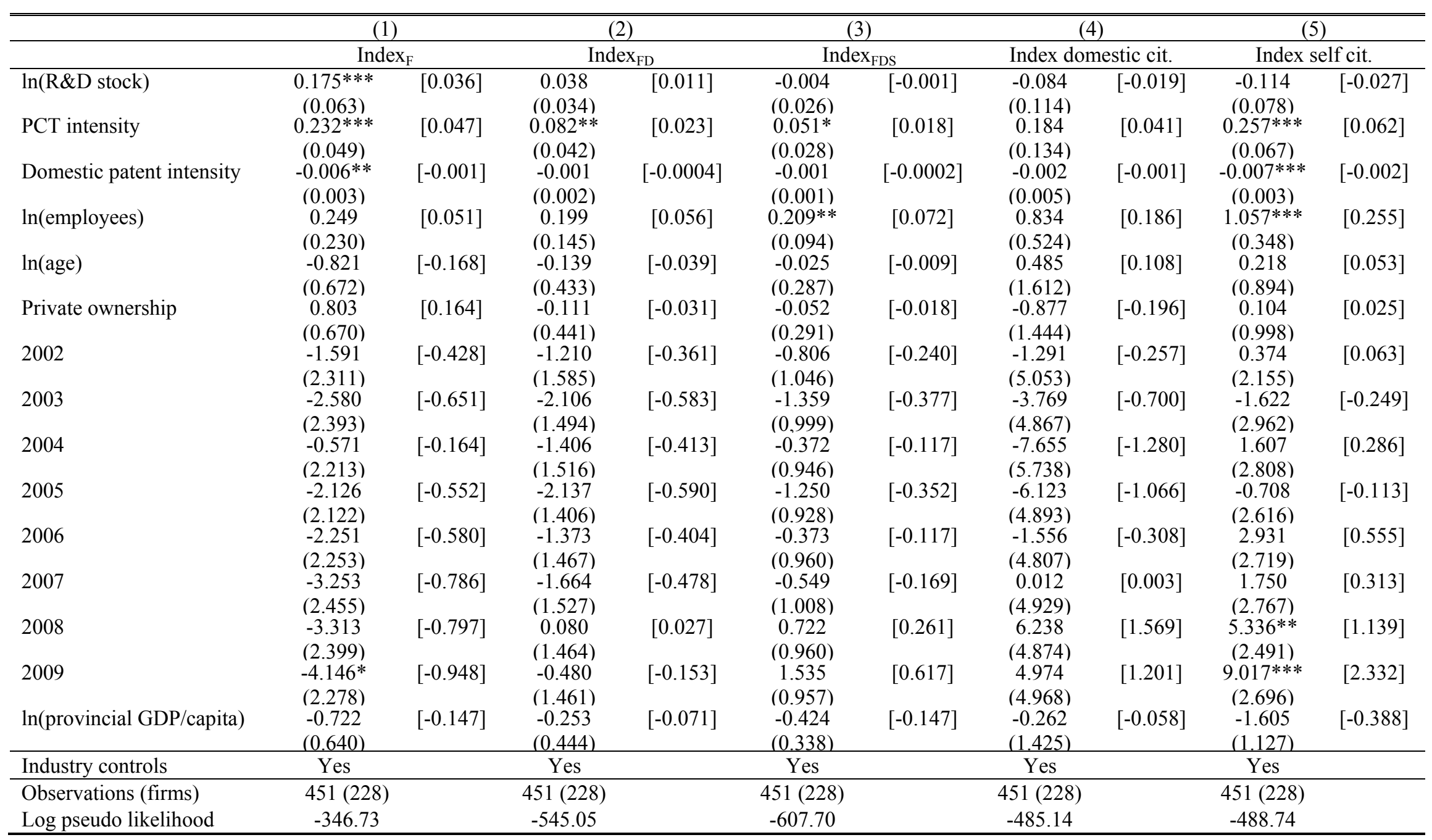

Note: Analysis at firm-year level. The dependent variable is the average quality index of a firm's annual patent applications. Tobit estimation with standard errors clustered at the firm-level. Average marginal effects are reported in square brackets. Reference category for year is 2001 . ***, **, * indicate statistical significance at the $1 \%, 5 \%$, and $10 \%$ levels. 
Table B4: Results of alternative estimations

\begin{tabular}{|c|c|c|c|c|c|c|c|c|}
\hline & \multicolumn{2}{|c|}{$(1)$} & \multicolumn{2}{|c|}{$(2)$} & \multicolumn{2}{|c|}{$(3 a)$} & \multicolumn{2}{|c|}{$(3 b)$} \\
\hline & \multicolumn{2}{|c|}{ Tobit } & \multicolumn{2}{|c|}{ RE Tobit } & \multicolumn{2}{|c|}{ Heckman (selection equation) } & \multicolumn{2}{|c|}{ Heckman (outcome equation) } \\
\hline & \multicolumn{2}{|c|}{ Index $_{F}$} & \multicolumn{2}{|c|}{ Index $_{\mathrm{F}}$} & \multicolumn{2}{|c|}{ PCT application $(0 / 1)$} & \multicolumn{2}{|c|}{ Index $_{F}$} \\
\hline $\ln (\mathrm{R} \& \mathrm{D}$ stock) & $\begin{array}{c}0.175 * * * \\
(0.063)\end{array}$ & {$[0.036]$} & $\begin{array}{c}0.190^{* * *} \\
(0.074)\end{array}$ & {$[0.038]$} & $\begin{array}{c}0.027 * * * \\
(0.004)\end{array}$ & {$[0.002]$} & $\begin{array}{c}0.029 * * * \\
(0.011)\end{array}$ & {$[0.012]$} \\
\hline PCT intensity & $\begin{array}{c}0.232 * * * \\
(0.049)\end{array}$ & {$[0.047]$} & $\begin{array}{c}0.229 * * * \\
(0.081)\end{array}$ & {$[0.046]$} & $\begin{array}{c}0.130 * * * \\
(0.009)\end{array}$ & {$[0.008]$} & $\begin{array}{c}0.028 * * \\
(0.014)\end{array}$ & {$[0.011]$} \\
\hline Domestic patent intensity & $\begin{array}{c}-0.006 * * \\
(0.003)\end{array}$ & {$[-0.001]$} & $\begin{array}{c}-0.008 * \\
(0.004)\end{array}$ & {$[-0.002]$} & $\begin{array}{c}0.0002 \\
(0.0004)\end{array}$ & {$[0.00001]$} & $\begin{array}{c}-0.001 \\
(0.0004)\end{array}$ & {$[-0.0003]$} \\
\hline $\ln ($ employees $)$ & $\begin{array}{c}0.249 \\
(0.230)\end{array}$ & {$[0.051]$} & $\begin{array}{l}-0.425 \\
(0.613)\end{array}$ & {$[-0.084]$} & $\begin{array}{c}0.310 * * * \\
(0.021)\end{array}$ & [0.019] & -- & -- \\
\hline $\ln ($ age $)$ & $\begin{array}{l}-0.821 \\
(0.672)\end{array}$ & {$[-0.168]$} & $\begin{array}{l}-4.103 * \\
(2.292)\end{array}$ & {$[-0.816]$} & $\begin{array}{l}-0.041 \\
(0.055)\end{array}$ & {$[-0.002]$} & $\begin{array}{c}-0.180 \\
(0.141)\end{array}$ & {$[-0.073]$} \\
\hline Private ownership & $\begin{array}{c}0.803 \\
(0.670)\end{array}$ & {$[0.164]$} & $\begin{array}{c}0.603 \\
(1.155)\end{array}$ & {$[0.120]$} & $\begin{array}{c}0.186^{* * *} * \\
(0.054)\end{array}$ & [0.011] & $\begin{array}{c}0.117 \\
(0.136)\end{array}$ & [0.048] \\
\hline $\ln ($ provincial GDP/capita) & $\begin{array}{l}-0.722 \\
(0.640)\end{array}$ & {$[-0.147]$} & $\begin{array}{c}0.448 \\
(3.948)\end{array}$ & [0.089] & $\begin{array}{c}0.350 * * * \\
(0.045)\end{array}$ & {$[0.021]$} & $\begin{array}{l}-0.113 \\
(0.140)\end{array}$ & {$[-0.046]$} \\
\hline Lambda & & & & & & & $\begin{array}{c}0.082 \\
(0.180) \\
\end{array}$ & \\
\hline Year controls & Yes & & Yes & & Yes & & Yes & \\
\hline Industry controls & Yes & & Yes & & Yes & & Yes & \\
\hline Rho & & & & & & & & \\
\hline Sigma & & & & & & & & \\
\hline Observations (firms) & $451(228)$ & & $451(228)$ & & & 12,575 & $1,743)$ & \\
\hline Log pseudo likelihood & -346.73 & & -342.31 & & & & & \\
\hline
\end{tabular}

Note: Analysis at firm-year level. The dependent variable is the average index $\mathrm{F}_{\mathrm{F}}$ of a firm's annual patent applications (models 1,2 and 4 ). The dependent variable of the first stage of the Heckman two-step selection model is a dummy indicating whether the firm has at least one PCT application (model 3). The RE Tobit model includes the Chamberlain-Mundlak device. Average marginal effects are reported in square brackets. ***,**,* indicate statistical significance at the $1 \%, 5 \%$, and $10 \%$ levels. 


\section{C) Additional analysis for PCT applications}

In Table $\mathrm{C} 1$ we report citation counts for Chinese and non-Chinese PCT applications. Between 2001 and 2009, the decline of index , from 44.9\% to $30.4 \%$ (as reported in Table 2 of the main paper), is a result of the decrease in the average number of citations obtained by Chinese PCT applications in comparison to the relatively stable number obtained by the comparison group. Similarly, the increases of index $\mathrm{FD}_{\mathrm{FD}}$ and index $\mathrm{FDS}$ are due to increases in the average number of citations obtained by Chinese PCT applications, whereas the citations obtained by the non-Chinese comparison group are also stable over time.

In order to consider the quality development of Chinese PCT applications from an international perspective, we calculate the average citation count according to the definition of index $_{\mathrm{F}}$ for the 19 largest applicant countries, including China. Table C2 provides the results when the technology composition of each country is weighted to reflect the distribution of China. This is done in order to present citation averages as they are used in the index calculation with China as the focal country. In our sample of 19 countries, China has the smallest average value of non-self-citations from foreign countries. Over the time period 2001-2009, we observe a decrease in the average number of citations for only four countries (JP, CN, CH, IT), a relatively constant level in the case of nine countries (DE, FR, GB, CA, IL, ES, DK, BE, AT), and an increase for six countries (US, KR, NL, SE, FI, AU).

To provide more general insight, we also present average citation counts according to the actual technology composition of each country. This corresponds to a country's general development, independent from the comparison with China (Table C3). China again has the smallest average citation count. In this representation, however, the count is decreasing in ten countries (US, JP, DE, FR, GB, CN, CH, IT, IL, BE), constant in eight countries (KR, NL, SE, CA, FI, ES, DK, AT), and increasing in one country (AU). 
Table C1: Citation counts for Chinese and non-Chinese PCT applications

\begin{tabular}{lcccccc}
\hline \hline \multicolumn{7}{c}{ Average citation counts } \\
\hline \hline & $\begin{array}{c}\text { Chinese } \\
\text { patents }\end{array}$ & $\begin{array}{c}\text { Non- } \\
\text { Chinese } \\
\text { patents }\end{array}$ & $\begin{array}{c}\text { Chinese } \\
\text { patents }\end{array}$ & $\begin{array}{c}\text { Non- } \\
\text { Chinese } \\
\text { patents }\end{array}$ & $\begin{array}{c}\text { Chinese } \\
\text { patents }\end{array}$ & $\begin{array}{c}\text { Non- } \\
\text { Chinese } \\
\text { patents }\end{array}$ \\
\hline 2001 & 0.131 & 0.276 & 0.165 & 0.424 & 0.217 & 0.587 \\
2002 & 0.079 & 0.249 & 0.108 & 0.371 & 0.144 & 0.528 \\
2003 & 0.085 & 0.241 & 0.112 & 0.348 & 0.148 & 0.499 \\
2004 & 0.074 & 0.224 & 0.088 & 0.317 & 0.143 & 0.448 \\
2005 & 0.091 & 0.230 & 0.126 & 0.323 & 0.199 & 0.442 \\
2006 & 0.074 & 0.258 & 0.154 & 0.364 & 0.262 & 0.495 \\
2007 & 0.075 & 0.292 & 0.235 & 0.414 & 0.407 & 0.545 \\
2008 & 0.077 & 0.302 & 0.311 & 0.431 & 0.627 & 0.580 \\
2009 & 0.076 & 0.292 & 0.325 & 0.426 & 0.781 & 0.576 \\
\hline Total & 0.079 & 0.276 & 0.234 & 0.396 & 0.473 & 0.536 \\
\hline
\end{tabular}

Note: Non-Chinese patents weighted according to the technology distribution of China. The values of "Chinese patents" and "non-Chinese patents" are the numerator and denominator values of the indices respectively. 
Table C2: Average foreign ISR citations of national PCT applications (Chinese technology composition)

\begin{tabular}{lccccccccccccccccccccccc}
\hline \hline & US & JP & DE & FR & KR & GB & NL & $C N$ & CH & SE & IT & CA & FI & AU & IL & ES & DK & AT & BE \\
\hline 2001 & 0.294 & 0.190 & 0.183 & 0.197 & 0.200 & 0.309 & 0.331 & 0.131 & 0.391 & 0.334 & 0.221 & 0.459 & 0.336 & 0.237 & 0.502 & 0.152 & 0.470 & 0.227 & 0.351 \\
2002 & 0.278 & 0.176 & 0.173 & 0.166 & 0.209 & 0.253 & 0.285 & 0.079 & 0.323 & 0.329 & 0.207 & 0.438 & 0.277 & 0.195 & 0.373 & 0.158 & 0.335 & 0.192 & 0.379 \\
2003 & 0.254 & 0.159 & 0.181 & 0.189 & 0.187 & 0.294 & 0.304 & 0.085 & 0.315 & 0.308 & 0.211 & 0.424 & 0.326 & 0.212 & 0.418 & 0.135 & 0.397 & 0.139 & 0.434 \\
2004 & 0.217 & 0.141 & 0.164 & 0.183 & 0.211 & 0.249 & 0.301 & 0.074 & 0.299 & 0.299 & 0.243 & 0.437 & 0.310 & 0.252 & 0.355 & 0.153 & 0.334 & 0.273 & 0.494 \\
2005 & 0.238 & 0.133 & 0.161 & 0.162 & 0.278 & 0.268 & 0.289 & 0.091 & 0.318 & 0.317 & 0.203 & 0.446 & 0.359 & 0.286 & 0.351 & 0.189 & 0.281 & 0.188 & 0.255 \\
2006 & 0.260 & 0.145 & 0.183 & 0.197 & 0.283 & 0.284 & 0.308 & 0.074 & 0.269 & 0.405 & 0.190 & 0.533 & 0.398 & 0.361 & 0.396 & 0.161 & 0.409 & 0.192 & 0.268 \\
2007 & 0.329 & 0.155 & 0.174 & 0.236 & 0.346 & 0.306 & 0.370 & 0.075 & 0.284 & 0.336 & 0.217 & 0.458 & 0.523 & 0.334 & 0.452 & 0.134 & 0.322 & 0.151 & 0.411 \\
2008 & 0.370 & 0.149 & 0.163 & 0.204 & 0.334 & 0.268 & 0.384 & 0.077 & 0.283 & 0.379 & 0.170 & 0.465 & 0.409 & 0.364 & 0.410 & 0.133 & 0.365 & 0.228 & 0.256 \\
2009 & 0.416 & 0.131 & 0.150 & 0.186 & 0.302 & 0.265 & 0.311 & 0.076 & 0.263 & 0.347 & 0.101 & 0.538 & 0.378 & 0.361 & 0.444 & 0.074 & 0.260 & 0.289 & 0.311 \\
\hline Aver. cit. & 0.331 & 0.145 & 0.165 & 0.196 & 0.295 & 0.276 & 0.330 & 0.079 & 0.285 & 0.351 & 0.172 & 0.487 & 0.399 & 0.330 & 0.417 & 0.128 & 0.328 & 0.221 & 0.325 \\
\hline
\end{tabular}

Note: Average annual citations with technology-composition of non-Chinese applications weighted according to 3-digit IPC composition of Chinese applications. The nationality of the PCT application is determined according to the country of the first applicant.

Table C3: Average foreign ISR citations of national PCT applications (national technology composition)

\begin{tabular}{lccccccccccccccccccccc}
\hline \hline & US & JP & DE & FR & KR & GB & NL & $C N$ & CH & SE & IT & CA & FI & AU & IL & ES & DK & AT & BE \\
\hline 2001 & 0.307 & 0.186 & 0.169 & 0.202 & 0.200 & 0.308 & 0.297 & 0.131 & 0.434 & 0.383 & 0.194 & 0.461 & 0.423 & 0.217 & 0.514 & 0.154 & 0.497 & 0.221 & 0.406 \\
2002 & 0.279 & 0.161 & 0.161 & 0.170 & 0.196 & 0.262 & 0.264 & 0.079 & 0.355 & 0.319 & 0.179 & 0.445 & 0.365 & 0.177 & 0.419 & 0.151 & 0.404 & 0.192 & 0.362 \\
2003 & 0.243 & 0.144 & 0.152 & 0.175 & 0.163 & 0.277 & 0.276 & 0.085 & 0.361 & 0.305 & 0.182 & 0.386 & 0.369 & 0.174 & 0.412 & 0.124 & 0.419 & 0.166 & 0.429 \\
2004 & 0.215 & 0.125 & 0.140 & 0.165 & 0.181 & 0.239 & 0.258 & 0.074 & 0.394 & 0.279 & 0.191 & 0.380 & 0.330 & 0.246 & 0.403 & 0.143 & 0.440 & 0.244 & 0.345 \\
2005 & 0.219 & 0.118 & 0.137 & 0.151 & 0.208 & 0.229 & 0.264 & 0.091 & 0.342 & 0.281 & 0.166 & 0.388 & 0.349 & 0.227 & 0.419 & 0.139 & 0.350 & 0.146 & 0.369 \\
2006 & 0.237 & 0.119 & 0.136 & 0.162 & 0.221 & 0.247 & 0.287 & 0.074 & 0.345 & 0.347 & 0.168 & 0.435 & 0.369 & 0.286 & 0.389 & 0.176 & 0.422 & 0.181 & 0.376 \\
2007 & 0.256 & 0.121 & 0.130 & 0.178 & 0.251 & 0.241 & 0.301 & 0.075 & 0.360 & 0.306 & 0.161 & 0.395 & 0.443 & 0.277 & 0.430 & 0.132 & 0.428 & 0.170 & 0.366 \\
2008 & 0.273 & 0.117 & 0.145 & 0.158 & 0.233 & 0.242 & 0.315 & 0.077 & 0.315 & 0.343 & 0.152 & 0.415 & 0.402 & 0.278 & 0.411 & 0.162 & 0.413 & 0.201 & 0.302 \\
2009 & 0.275 & 0.101 & 0.136 & 0.143 & 0.184 & 0.209 & 0.299 & 0.076 & 0.312 & 0.300 & 0.127 & 0.415 & 0.318 & 0.288 & 0.410 & 0.116 & 0.356 & 0.172 & 0.307 \\
\hline Aver. cit. & 0.257 & 0.118 & 0.139 & 0.159 & 0.211 & 0.235 & 0.293 & 0.079 & 0.338 & 0.315 & 0.155 & 0.411 & 0.370 & 0.266 & 0.414 & 0.141 & 0.398 & 0.181 & 0.342 \\
\hline Total PCT & 360,691 & 201,681 & 138,23 & 52,167 & 44,343 & 42,699 & 35,369 & 34,738 & 27,186 & 26,139 & 21,214 & 19,122 & 15,658 & 13,960 & 11,329 & 9,639 & 9,252 & 7,420 & 7,401 \\
\hline
\end{tabular}

Note: Total PCT is the sum of the respective national PCT applications between 2001 and 2009. The nationality of the PCT application is determined according to the country of the first applicant. 


\section{Additional References for Appendix}

Hegde, D. and Sampat, B., Examiner citations, applicant citations, and the private value of patents. Economics Letters 105, 287-289 (2009).

Jaffe, A. B., Trajtenberg, M., and Henderson, R., Geographic localization of knowledge spillovers as evidenced by patent citations. Quarterly Journal of Economics 63, 577-598 (1993).

Kaemmer, C., Searching Chinese patent information on free online sources. Business Information Review 27, 39-42 (2010).

Peri, G., Determinants of knowledge flows and their effect on innovation. Review of Economic Studies 87, 308-322 (2005).

Pistor, K. and $\mathrm{Xu}, \mathrm{C}$., Governing stock markets in transition economies: lessons from China. American Law \& Economics Review 7, 184-210 (2005).

State Intellectual Property Office of P. R. China, “Opinions of the State Intellectual Property Office to further enhance the quality of patent applications" (2013).

State Intellectual Property Office of P. R. China, "Interpretation of opinions of the State Intellectual Property Office to further enhance the quality of patent applications" (2014). WIPO, "Regulations under the Patent Cooperation Treaty" (Publication WIPO, 2014c). 